\section{AB0084 BREADTH OF BASELINE AUTOANTIBODY PROFILE AND TREATMENT RESPONSE IN RHEUMATOID ARTHRITIS PATIENTS}

V.F.A.M. Derksen ${ }^{1}$, E.C. de Moel ${ }^{1}$, L.A. Trouw ${ }^{1}$, R.J. Goekoop ${ }^{2}$, I. Speyer ${ }^{3}$, T.W.J. Huizinga ${ }^{1}$, C.F. Allaart ${ }^{1}$, R.E.M. Toes ${ }^{1}$, D. van der Woude ${ }^{1}$.

${ }^{1}$ Rheumatology, Leiden University Medical Center, Leiden; ${ }^{2}$ Rheumatology, Haga Hospital; ${ }^{3}$ Rheumatology, Haaglanden Medical Center, The Hague, Netherlands

Background: Seropositive and seronegative rheumatoid arthritis (RA) are distinct disease entities with regard to pathophysiological mechanisms and disease outcomes. However, over the past years it has become clear that the autoantibody profile of seropositive RA is very diverse, involving multiple post-translational modifications and isotypes, and it seems unlikely that a single autoantibody will be informative for identifying groups at risk of poor treatment response. Instead of individual autoantibodies, we hypothesized that the breadth of seropositive patients' profile may be the best reflection of the underlying immunopathology, and would be able to identify homogenous treatment response and inform treatment decisions.

Objectives: To investigate whether baseline autoantibody profile is associated with treatment response and the ability to taper off medication in RA patients. Methods: All RA patients fulfilling the 2010 ACR/EULAR Criteria included in the IMPROVED study ${ }^{1}$ that were seropositive for routine clinical testing for anti-cyclic citrullinated peptide-2 (anti-CCP2 $\lg$ ), rheumatoid factor (RF $\operatorname{lgM}$ ), or our in-house assay for anti-carbamylated protein antibodies (anti-CarP IgG) were selected $(n=381)$. In baseline sera of these patients, we measured IgG, $\lg \mathrm{M}$, and IgA isotypes for each family (except $\lg \mathrm{G}$ for $\mathrm{RF}$ ) and reactivity against 4 citrullinated peptides (cit-vimentin 59-74, cit-fibrinogen $\beta 36-52$ and $\alpha 27-43$, and cit-enolase $5-20$ ). We investigated associations between autoantibody profile and 1) change in disease activity score (DAS)-44 over time and 2) sustained drug-free remission, defined as the ability to taper off medication and remain in remission for $\geq 1$ year after achieving DAS $44<1.6$.

Results: The initial treatment response (mean $\triangle$ DAS 0-4 months) in seropositive patients with a broad autoantibody profile (7-8 isotypes present) was better than in those with fewer isotypes present ( $\triangle$ DAS $0-4$ months of 7-8 isotypes vs $1-2,3-4$, and $5-6$ isotypes, respectively: -2.2 vs $-1.5[p<0.001],-1.7[p=0.04]$, and $-1.8[p=0.04])$. In contrast, the presence of multiple autoantibodies was unfavorable regarding the long-term outcome of sustained drug-free remission. Within seropositive disease, patients with more isotypes and more reactivities to citrullinated peptides significantly less often achieved sustained drug-free remission (SDFR) (Figure).

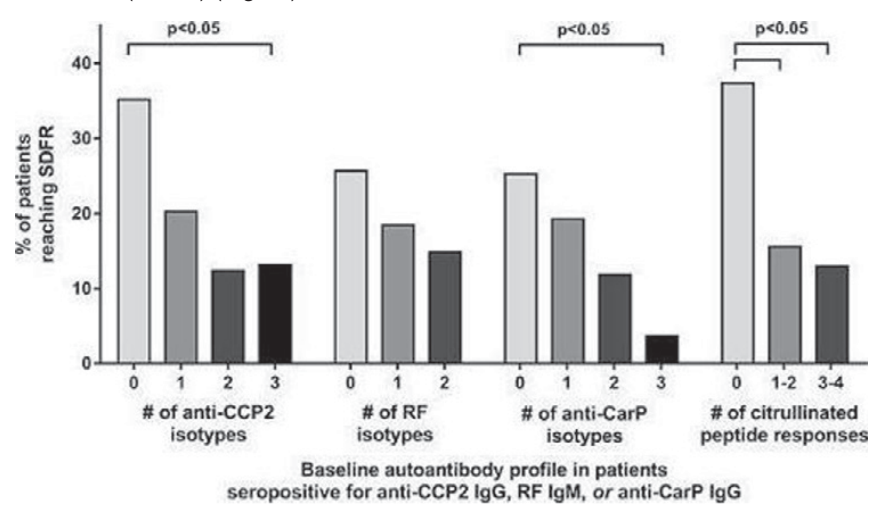

Conclusions: Seropositive patients with a broader autoantibody profile at baseline initially react better to treatment, but are not able to taper off medication and remain in remission. This may be relevant in individualized decision-making for tapering medication, as these results suggest that disease with a broad autoantibody response, as proxy for an active humoral autoimmunity, is more difficult to control in the long-term without sustained therapy.

References:

[1] Heimans, AR\&T 2016, 18:23.

Disclosure of Interest: None declared

DOI: 10.1136/annrheumdis-2017-eular.3193

\section{AB0085 INTERACTION OF HLA-SHARED EPITOPE (SE) AND SMOKING ON THE DEVELOPMENT OF ANTI-CCP POSITIVE RHEUMATOID ARTHRITIS IN GREEK POPULATION}

E.N. Mole ${ }^{1}$, K. Tarassi ${ }^{2}$, V. Kitsiou ${ }^{2}$, T. Athanassiades ${ }^{2}$, D. Kouniaki ${ }^{2}$, K. Soufleros ${ }^{2}$, C. Korkou ${ }^{1}$, A. Tsirogianni ${ }^{2}$, C. Sfontouris ${ }^{1} .{ }^{1}$ Department of Rheumatology; ${ }^{2}$ Department of Immunology-Histocompatibility, Evangelismos General Hospital, Athens, Greece

Background: Rheumatoid Arthritis (RA) is a complex, multifactorial autoimmune disease, whose etiopathogenesis involves genetic and environmental factors.

Objectives: The aim of the study was the assessment of the association of HLA-DRB1*-SE in the presence/absence of anti-CCP autoimmunity in Greek patients with RA (smokers and non-smokers).
Methods: Eighty-three (83) RA patients (41 smokers, 42 have never smoked) were typed for HLA-DRB1* alleles by molecular techniques (PCR-SSOP and -SSP). In 62 out of $83(74.7 \%)$ anti-CCP abs were detected by ELISA.

Results: In RA pts and in comparison to the controls, increased frequency of HLA-DRB $1{ }^{*} 01: 01$ (28.9\% vs $6.8 \%$, OR $\left.=4.4\right),{ }^{*} 10: 01$ (16.9\% vs $2.4 \%$, OR=8.4), ${ }^{*} 04: 01$ (3.6\% vs $2 \%$, OR=1.8), ${ }^{*} 04: 04\left(7.2 \%\right.$ vs $1 \%$, OR=7.6) and ${ }^{*} 04: 05(15.7 \%$ vs $3.7 \%, \mathrm{OR}=4.8)$, as well as decreased frequency of ${ }^{*} 04: 02(1.2 \%$ vs $2 \%$, $\mathrm{OR}=0.6)$ and ${ }^{*} 04: 03(4.8 \%$ vs $6.8 \%, \mathrm{OR}=0.7)$ were found. Among the $\mathrm{RA}$ patients, $77.1 \%$ possess $1 \mathrm{SE}$ vs $18.9 \%$ of controls (OR=14.4), whereas $10.8 \%$ possess $2 \mathrm{SE}$ vs $1 \%$ of controls $(\mathrm{OR}=11.8)$. In $\mathrm{CCP}(+) \mathrm{RA}$ patients and in comparison to CCP (-) an increased frequency of HLA-DRB1*01:01 $(27.4 \%$ vs $14.3 \%, \mathrm{OR}=2.3$ ) and ${ }^{*} 10: 01$ (21\% vs $\left.4.8 \%, \mathrm{OR}=5.3\right)$ was observed. Furthermore, $88.7 \%$ of CCP $(+)$ carry 1 SE vs $42.9 \%$ of $\operatorname{CCP}(-)$ patients (OR=10.5). CCP $(+)$ smokers patients in comparison to CCP $(+)$ non-smokers are presented with an increased frequency of $\mathrm{DRB} 1{ }^{*} 01: 01(41.9 \%$ vs $12.9 \%$, OR=4.9). Among the CCP $(+)$ smokers, $96.8 \%$ possess $1 \mathrm{SE}$ vs $80.6 \%$ of CCP $(+)$ non-smokers $(\mathrm{OR}=7.2)$, whereas $12.9 \%$ possess 2 SE vs $12.9 \%$ of CCP $(+)$ non-smokers $(\mathrm{OR}=1)$.

Conclusions: a) An increased frequency of HLA-DRB1*01:01, ${ }^{*} 10: 01$, ${ }^{*} 04: 05$ alleles, as well as the protective role of *04:02, *04:03 alleles in Greek patients with RA were confirmed b) The presence of any SE, particularly *10:01 allele, strongly influences the production of anti-CCP abs and c) Interaction between smoking and any SE, particularly *01:01 allele, is associated with anti-CCP positive RA in Greek patients.

\section{References:}

[1] Klareskog L, Stolt P, Lundberg K, Kallberg H, Bengtsson C, Grunewald J, et al. A new model for an etiology of rheumatoid arthritis: smoking may trigger HLA-DR (shared epitope)-restricted immune reactions to autoantigens modified by citrullination. Arthritis and rheumatism. 2006;54(1):38-46.

[2] Ioannidis JP, Tarassi K, Papadopoulos IA, Voulgari PV, Boki KA, Papasteriades $\mathrm{CA}$, et al. Shared epitopes and rheumatoid arthritis: disease associations in Greece and meta-analysis of Mediterranean European populations. Seminars in arthritis and rheumatism. 2002;31(6):361-70.

[3] Lee YH, Bae SC, Song GG. Gene-environmental interaction between smoking and shared epitope on the development of anti-cyclic citrullinated peptide antibodies in rheumatoid arthritis: a meta-analysis. International journal of rheumatic diseases. 2014;17(5):528-35.

Disclosure of Interest: None declared

DOI: 10.1136/annrheumdis-2017-eular.5213

\section{AB0086 PREVENTIVE EFFECTS OF ANGIOTENSIN 1-7 ON NEOANGIOGENESIS AND LEUKOCYTE TRAFFICKING INCREASE IN THE EARLY PHASES OF AN EXPERIMENTAL MODEL OF ANTIGEN INDUCED ARTHRITIS}

F. Fischetti, P. Durigutto, D. De Nardo, R. Carretta. University of Trieste Italy, Trieste, Italy

Background: Renin Angiotensin System (RAS) might be supposed to be involved in the early and late phases of development of synovitis, since data exist showing that Angiotensin (AT)-II contributes to the development of vascular damage under early inflammatory conditions $(1,2)$. Little is known about AT 1-7 functions, which is supposed to play counteracting actions vs AT II, under these conditions $(2,3)$ Objectives: to evaluate if, in the early phases of an experimental model of arthritis, namely the antigen-induced arthritis (AIA), treatment with AT 1-7 could interfere with the synovial development of capillary vascular growth, and prevent leukocyte trafficking activation, in vivo, either at synovial and at mesentery post-capillary venules.

Methods: in compliance with European (86/609/EEC) and the Italian (D.L.116/92) ethics committees, 2 groups each of 8 male (240-270 gr) Wistar rats were randomly chosen and treated respectively with sterile saline, or with AT 1-7 $(576 \mu \mathrm{g} / \mathrm{kg} / \mathrm{day})$, during the time of immunization with methylated serum bovine albumin (mBSA). Arthritis was induced by intraarticular administration of mBSA $(0.1 \mathrm{mg}$ in $100 \mathrm{ml}$ sterile saline) into the right knee of each animal, after previous immunization to mBSA emulsified in complete Freund's adjuvant. The left knee, injected with only saline, served as a control. Two and 5 days after arthritis induction, the count of capillary branches, and the number of fluorescently-labelled leukocytes, showing transient or stable adhesion to the endothelial microvascular layer (EL), were assessed by using an in vivo videomicroscopy technique. Results: synovial branching vessels with diameter $>20 \mu \mathrm{m}$ were not modified after AIA induction, while microvessels having diameter less than $20 \mu \mathrm{m}$ were significantly increased. After 2 and 5 days, AT 1-7 reduced the number of neo expressed $<20 \mu \mathrm{m}$ diameter vessels (Day2: $3.7 \pm 3.4$ vs $7.7 \pm 5.05, p=n s$; Day5: $12.7 \pm 6.9$ vs $21.0 \pm 7.3, p<0.05$; both significantly greater than control joints). Transient and stable adhesion to EL showed to be partially reduced 2 days after $\mathrm{AIA}$ induction and significantly reduced after 5 days (Day5, transient $=12.5 \pm 6.2$ vs $26.0 \pm 9.0, \mathrm{p}<0.05$; stable $=27.0 \pm 8.3$ vs $41.7 \pm 10.6, \mathrm{p}<0.05$; both significantly greater than control joints). Comparable results were found when analysing the number of leukocytes adhering to mesentery EL.

Conclusions: we suggest that AT 1-7 could play an immune modulating role in the early phase of synovitis with possible prevention of further inflammatory and secondary structural tissue alterations. These data further support the hypothesis that mechanisms leading to synovial AT-II activation have a detrimental role in the development of arthritis. 
References:

[1] Candido R, et al. Circulation 2004;109:1536-1542.

[2] Zhang F et al, Sci Rep. 2016; 6: 34621.

[3] Villalobos LA et al, Front Pharmacol. 2016; 7: 482

Disclosure of Interest: None declared

DOI: 10.1136/annrheumdis-2017-eular.5493

\section{AB0087 SONIC HEDGEHOG PROMOTES FIBROBLAST-LIKE SYNOVIOCYTES PROLIFERATION VIA MODULATING THE MAPK/ERK SIGNALING PATHWAY IN RHEUMATOID ARTHRITIS}

F. Liu ${ }^{1}$, S.-L. Zhu ${ }^{2}$, Y.-F. Pan ${ }^{1}$, J.-L. Huang ${ }^{2} .{ }^{1}$ Rheumatology, the Third Affiliated Hospital of Sun Yat-Sen University; ${ }^{2}$ Rheumatology, the Sixth Affiliated Hospital of Sun Yat-Sen University, Guangzhou, China

Background: The Sonic hedgehog (Shh) signaling has been reported to be activated in synovium of RA patients and RA-FLS in vitro [1]. Further, Shh signaling plays an important role in RA-FLS proliferation [2]. As for the extracellular signal-regulated kinase (ERK), is a member of mitogen-activated protein kinase (MAPK) [3], which has been reported to be involved in proliferation of RA-FLS [4]. However, the role of MAPK/ERK signaling pathway in the proliferation of RA-FLS modulating by Shh is unclear.

Objectives: To study the effect of MAPK/ERK signaling pathway on cell proliferation modulated by Sonic hedgehog (Shh) signaling in fibroblast-like synoviocytes isolated from patients with active rheumatoid arthritis (RA-FLS).

Methods: The RA-FLS were primarily cultured by the explant culture, and then were treated with Shh agonist Purmorphamine,inhibitor Cyclopamine or MAPK/ERK signaling pathway inhibitor U0126, respectively. Western blots was used to examine the phosphorylation level of ERK 1/2 (p-ERK1/2), which was the critical protein of MAPK/ERK signaling. The cell proliferation activity was detected using cell proliferation and cytotoxicity kit-8 (CCK8), and the cell proliferation rate was detected using a flow cytometry.

Results: Compared with the control group, Purmorphamine transiently increased p-ERK $1 / 2$ protein at the concentration of $1 \mu \mathrm{M}$, and the peak activations of p-ERK $1 / 2$ took place at $15 \mathrm{~min}(P<0.01)$. Cyclopamine and $\mathrm{U} 0126$ decreased the expression of $\mathrm{p}$-ERK $1 / 2$ protein $(P<0.01)$. After the RA-FLS treated with Purmorphmine $(1 \mu \mathrm{M})$ for 48 hours, the cell proliferation activity was $114 \pm 4 \%$ and the percentage of $S$ phase cells was $8.39 \pm 0.60 \%$, significantly higher than those of the control group $100 \pm 0 \%(P<0.01)$ and $3.29 \pm 0.69 \%(P<0.01)$. After treated with Cyclopamine $(10 \mu \mathrm{M})$ for 48 hours, the cell proliferation activity of RA-FLS was $89 \pm 1 \%(P<0.05)$ and the percentage of $S$ phase cells was $1.53 \pm 0.22 \%$ $(P<0.05)$. When co-treated with purmorphamine $(1 \mu \mathrm{M})$ and $\mathrm{U} 0126(10 \mu \mathrm{M})$, the cells proliferative activity was $892 \%(P<0.05)$ and the percentage of $S$ phase cells was $1.07 \pm 0.25 \%(P<0.05)$.

Conclusions: Shh might promote proliferaton of RA-FLS via modulating MAPK/ERK signaling, subsequently contributing to hyperlasia of synovium and ultimately leading to RA disease.

References:

[1] Wang M, et al. Sonic hedgehog signaling drives proliferation of synoviocytes in rheumatoid arthritis: a possible novel therapeutic target[J]. J Immunol Res, 2014, 2014: 401903.

[2] Zhu SL, et al. Inhibition of smoothened decreases proliferation of synoviocytes in rheumatoid arthritis[J]. Cell Mol Immunol, 2015. DOI: 10.1038/cmi.2015.67.

[3] Elia D, et al. Sonic hedgehog promotes proliferation and differentiation of adult muscle cells: Involvement of MAPK/ERK and PI3K/Akt pathways[J]. Biochim Biophys Acta, 2007. 1773(9): 1438-46.

[4] Morel J, Audo R, Hahne M, Cet al. umor necrosis factor related apoptosis inducing ligand (TRAIL) induces rheumatoid arthritis synovial fibroblast proliferation through mitogen activated protein kinases and phosphatidylinositol3kinase/Akt[J]. J Biol Chem 2005. 280(16):15709-15718.

Acknowledgements: This study was supported by the National Natural Science Foundation of China (No.81571584). I thank Jianlin Huang for protocols.

Disclosure of Interest: None declared

DOI: 10.1136/annrheumdis-2017-eular.4027

\section{AB0088 THE ROLE OF HIGH MOBILITY GROUP BOX-1 (HMGB1) IN INFLAMMATORY VASCULOPATHY IN COLLAGEN ANTIBODY-INDUCED ARTHRITIS (CAIA)}

F. Biscetti ${ }^{1}$, A. Flex ${ }^{2}$, F. Angelini ${ }^{2}$, E. Gremese ${ }^{1}$, B. Tolusso ${ }^{1}$, G. Ferraccioli ${ }^{1}$ ${ }^{1}$ Rheumatology; ${ }^{2}$ Internal Medicine, Catholic University School of Medicine, Rome, Italy

Background: Rheumatoid arthritis (RA) is associated with vascular disease (1). Recent findings demonstrated that the risk of peripheral arterial occlusive disease is increased in patients with RA compared to the general population (2). However, the pathogenesis is not fully understood. High-mobility group box-1 (HMGB1) is a nuclear protein involved in inflammatory responses (3) and RA-like synovitis (4). Objectives: Aim of the present study was to analyze the relationship between HMGB1 and peripheral arterial disease in collagen antibody-induced arthritis (CAIA).

Methods: BALB/c mice were injected with monoclonal anti-collagen antibody cocktail followed by lipopolysaccharide to induce arthritis. After the induction of arthritis, we studied ischemia-induced neovascularization in the ischemic hind limb of arthritic and control mice.

Results: We found that the perfusion recovery was significantly attenuated arthritic mice, compared to control mice. The immunohistochemical analysis for the CD31 demonstrated a reduced number of vessel in mice with experimental arthritis. The selective blockade of HMGB1 in arthritic mice resulted in restored blood flow recovery and capillary density in the ischemic muscle. Cytokine enzyme-linked immunosorbent assay (ELISA) analyses performed on peripheral blood demonstrated a significant reduction of interleukin (IL)-1 $\beta$, IL-6 and tumor necrosis factor (TNF)- $\alpha$ in mice where HMGB1 was blocked. Interestingly, the selective blockade of HMGB1 resulted in an increase of the peripheral IL-17A concentration.

Conclusions: HMGB1 pathway is involved in an experimental vasculopathy induced in a RA-like model. The proangiogenic cytokine IL-17A is increased when HMGB1 is inhibited. Although further data are needed, these findings provide new evidence regarding the pathogenesis of vascular complications observed in patients with RA.

\section{References:}

[1] Roman MJ, Salmon JE. Cardiovascular manifestations of rheumatologic diseases. Circulation. 2007 Nov 13;116(20):2346-55.

[2] Chuang YW, Yu MC, Lin CL, Yu TM, Shu KH, Huang ST, Kao CH. Risk of peripheral arterial occlusive disease in patients with rheumatoid arthritis. A nationwide population-based cohort study. Thromb Haemost. 2016 Jan;115(2):439-45.

[3] Biscetti F, Ghirlanda G, Flex A. Therapeutic potential of high mobility group box-1 in ischemic injury and tissue regeneration. Curr Vasc Pharmacol. 2011 Nov:9(6):677-81.

[4] Biscetti F, Flex A, Pecorini G, Angelini F, Arena V, Stigliano E, Gremese E, Tolusso B, Ferraccioli G. The role of high-mobility group box protein 1 in collagen antibody-induced arthritis is dependent on vascular endothelial growth factor. Clin Exp Immunol. 2016 Apr;184(1):62-72.

Disclosure of Interest: None declared

DOI: 10.1136/annrheumdis-2017-eular.4111

\section{AB0089 ELECTROKINETIC CHARACTERISTICS OF SYNOVIOCYTES (SC) AND THE LEVEL OF ANTIOXIDANT PROTECTION IN RHEUMATOID ARTHRITIS (RA)}

G. Kudriavtseva, V.I. Shishkin, V.V. Shishkin, Y.A. Malenkov. Saint Petersburg State University, Saint Petersburg, Russian Federation

Background: Known role of SC in the pathogenesis of RA. It is impossible, however, at this level of knowledge to ascertain all the mechanisms for their involvement in the pathological process. Reduced tissue antioxidant protection can affect cellular metabolism, and as might be expected, through the mechanism of autophagy inducing mitochondrial and lysosomal degradation, facilitating cell membrane depolarization.

Objectives: The aim of this work was to study the electrophoretic mobility (EM) of $\mathrm{SC}$ of RA patients and its relationship with the activity of antioxidant enzymes: Cu-Zn superoxidismutase (Cu-Zn SOD), Se-glutathione peroxidase (Se-GPO) and catalase (the CAT) in synovial fluid (SF).

Methods: SF has been obtained from the knee of 7 patients with RA and 5 donors. SC isolated by standard methods. EM of SC determined by the automatic microscope. Se level in SF recorded by atomic absorption spectrometry. The activity of the antioxidant enzymes was determined by classical methods of enzymology.

Results: A significant depolarization of the RA SC, resulting in a reduction of their EM as compared to the normal level of the average in 4 times. Activity of antioxidant enzymes is dramatically reduced by a significant decrease of Se concentrations in SF $(150 \mu \mathrm{g} / \mathrm{l}$ normally up to $80 \mu \mathrm{g} / \mathrm{l}$ in RA), which is particularly reflected in the activity of Se GPO (note that SF can be up to 100 Se-containing proteins).

\begin{tabular}{lcccc} 
Table 1 & \multicolumn{5}{c}{} \\
\hline & $\begin{array}{l}\text { EM of SC } \\
(\mathrm{m} / \mathrm{v} \mathrm{sec})\end{array}$ & $\begin{array}{c}\text { Cu-Zn SOD } \\
(\text { Units } / \mathrm{mg} \text { of protein })\end{array}$ & $\begin{array}{c}\text { Se-GPO } \\
(\text { Units } / \mathrm{mg} \text { of protein })\end{array}$ & $\begin{array}{c}\text { CAT } \\
(\mu \mathrm{mol} / \mathrm{min} / \mathrm{mg} \text { of protein) }\end{array}$ \\
\hline Normal SF & $1,62 \times 10^{-8}$ & $23,4 \pm 0,8$ & $1,3 \pm 0,3$ & $10,3 \pm 0,1$ \\
RA SF & $0,37 \times 10^{-8}$ & $11,7 \pm 0,4$ & $0,4 \pm 0,1$ & $0,47 \pm 0,04$ \\
\hline
\end{tabular}

Conclusions: We can assume that aggravated by RA catabolic processes that caused the dysfunction of the lysosomal and mitochondrial structures (autophagy), consistently shoot antioxidant protection of SC and cause depolarization and the decrease in electrophoretic mobility of these cells.

Disclosure of Interest: None declared

DOI: 10.1136/annrheumdis-2017-eular.5364 